\title{
REPRODUCTIVE PHENOLOGY, FLORAL BIOLOGY AND BREEDING SYSTEM OF AQUILIARIA CRASSNA IN TROPICAL AUSTRALIA
}

\author{
López-Sampson $\mathrm{A}^{1, *} \&$ Page $\mathbf{T}^{2}$ \\ ${ }^{1}$ College of Science and Engineering, James Cook University, Cairns, Australia 4878 \\ ${ }^{2}$ Tropical Forests and People Research Centre, University of Sunshine Coast, Maroochydore, Australia 4558 \\ *arlene.lopezsampson@gmail.com
}

Submitted April 2018; accepted October 2018

\begin{abstract}
Trees of the Aquilariagenus produce a fragrant resin and have had a long history of human use. In this study, the flowering and fruiting phenology of Aquilaria crassna is described, as well as the main reproductive system operating in A. crassna, growing in a cultivated environment. Sexual reproduction occurs annually, with a peak in flowering occurring during the dry season. Flowers are hermaphrodite borne on terminal branches. Flower anthesis typically occurred at night and the duration of the flowering and fruiting phases was 12.3 and 59.5 days respectively. Four simplified flower stages were identified: opening ( 0.2 to 1 day), open (2.3 to 3.6 days), closing ( 0.8 to 1.3 days) and closed-flower fall (1.4 to 7.4 days) or closed-fruit development (17 to 25 days). Stigma receptivity, determined using an esterase indicator, was recorded throughout the floweropen phase. Two simplified fruiting stages were identified: initiation ( 4 to 8 days) and maturation (25 to 58 days). Open pollinated flowers had a moderate to high fecundity with 14.5 to $46.7 \%$ of flowers setting seed. The A. crassna species demonstrated a mixed mating system that is primarily outcrossing. Hybridisation between A. baillonii ( $\hat{(})$ and A. crassna () was demonstrated.
\end{abstract}

Keywords: Compatibility, controlled pollination, flower development, hybridisation, plant reproduction

\section{INTRODUCTION}

The genus Aquilaria produces a valuable fragrant resin, known as agarwood, widely used for the production of incense, perfume and for medical purposes (López-Sampson \& Page 2018). Several species of the genus have been reported as a source of the resin (Persoon 2008). The resin develops and accumulates in the stem and branches of the tree after a process of injury or pathogen attack (Donovan \& Puri 2004, Rasool $\&$ Mohamed 2016). Only a few trees in natural areas (2-3\% of the total population) can yield the highly sought resin (Ng et al. 1997). This has led to the overexploitation of the genus in the countries of origin (Soehartono \& Newton 2000, Persoon 2008).

Cultivation of Aquilaria offers an opportunity for establishing a sustainable commercial source of agarwood and reducing the harvesting pressure in natural populations (Nakashima et al. 2005, Persoon 2008). Plantings of Aquilaria species have been established in Laos, Bangladesh, Indonesia, Cambodia, Malaysia, Vietnam and Australia (Rahman \& Khisa 1984, Barden et al. 2000, Donovan \& Puri 2004, Page \& Awarau
2012). Efforts have also been made to understand the process of resin formation with the view to developing methods for resin induction to improve the viability of cultivated agarwood (Liu et al. 2013, Mohamed et al. 2014, Persoon 2008) . While the development of resin induction techniques is central to agarwood production in plantations, other traits will also influence cultivation success. These may include growth rate, tree form, environmental and edaphic adaptability, propensity to respond to artificial induction, resin production and quality (Akter et al. 2013, Azren et al. 2018). Understanding the variation in these traits provides the basis for selection and is of particular significance in crop improvement. Of equal importance to crop improvement is the development of methods for capturing these traits in current and subsequent generations through vegetative and sexual reproduction (Parr \& Cameron 2004). Knowledge of reproductive biology is essential in crop improvement as it will guide the methods for conducting controlled pollination and hybridisation, and influence 
the domestication strategy. With wider planting of different agarwood species in cultivated landscapes, there is now a greater possibility of interspecific interaction, but the understanding of the potential for spontaneous hybridisation among them is limited. Understanding the breeding system will therefore be a key element for the domestication and improvement of Aquilaria and revealing potential gene flow within and among plantations.

Previous research on the reproductive biology of Aquilaria indicates that flowers are hermaphroditic and borne on terminal branches. The duration of all reproduction stages (budding, flowering and fruiting in days) among six species of Aquilaria (A. beccariana, A. crassna, A. filaria, A. hirta, A. malaccensis and A. microcarpa) varied widely among species, reportedly 44.6 days for A. filaria, 49.4 days for $A$. crassna, 51.4 days for $A$. microcarpa, 59.3 days for $A$. beccariana, 77.7 days for A. hirta and 82.4 days for A. malaccensis (Soehartono \& Newton 2001). The results of fruit set in bagged flowers (to limit open pollination) of three species of Aquilaria (A. filaria, $A$. malaccensis and $A$. microcarpa) demonstrated no capacity for autogamous spontaneous pollination (Soehartono \& Newton 2001).

In this research particular attention was given to A. crassna as one of the most planted species in reforestation schemes to produce agarwood. This study was undertaken to improve the understanding of the reproductive biology of $A$. crassna. The aims of this study was (i) to study the reproductive phenology of $A$. crassna, specifically identify and describe modification in flower appearance from bud stage to flower senescence and fall or fruit initiation, (ii) to determine the onset and duration of stigma receptivity and (iii) to determine levels of self- and cross-compatibility within $A$. crassna, and cross-compatibility of $A$. crassna with A. baillonii and A. subintegra.

\section{METHODOLOGY}

\section{Site description and tree selection}

Description of the reproductive phenology and breeding system of Aquilaria crassna were conducted in individuals growing in a research plantation located near Innisfail, north Queensland, Australia (17.52 $\left.{ }^{\circ} \mathrm{S}, 146.02{ }^{\circ} \mathrm{E}\right)$. Annual rainfall in this site is about $3560 \mathrm{~mm}$ with most falling between November and April during the monsoonal wet season with a mean annual temperature of about $24.3{ }^{\circ} \mathrm{C}$ (Page \& Awarau
2012). A research plantation was established in January 2010 using wild-collected seed from certified nurseries consisting primarily of $A$. crassna and smaller introductions from A. bailonii and A. subintegra from locations in mainland Southeast Asia. Trees were grown in full sun and were subject to standard silvicultural (pruning) and agronomic practices (fertilisation, weed and pest control). Trees were selected based on being reproductively mature and having flowers available during the peak of the flowering season (October-November).

\section{Reproductive phenology in A. crassna}

Two discrete observation periods were used to describe the reproductive phenology in A. crassna. The first observation period was conducted between October and December 2012 and the second between October and January 2015/2016. The time lapse between observations was due to time constraints and personnel availability to photograph the reproductive structures.

In season 2012, flowers and fruit in seven inflorescences from three trees of $A$. crassna were photographed across three timing intervals 1) daily over a period of 30 days (from bud stage to flower fall), 2) every two days the next 12 days (to monitor changes in fruit formation) and 3) every four days the next 45 days (fruit maturity and seed production). The duration (in days) of each flowering or fruiting phase was recorded from the period of anthesis to flower fall or fruit maturity and seed production for all flowers in each inflorescence. The day of anthesis for the first flower in a given inflorescence was considered Day 1 for the development of the inflorescence and in-frutescence. In season 2015/2016 the sequence of flower and inflorescence development was assessed in single inflorescences on three different trees of $A$. crassna. In this season the frequency of shooting was augmented to document any changes in hours. Photographs were taken twice daily $(0700$ and $1900 \mathrm{hrs}$ ) over the reproductive season (October-January) in 2015/2016.

\section{Flowers changes during anthesis and fruit formation}

Based on the sequence of photographs taken in 2012 and 2015/2016 seasons, a simple consecutive scale describing flower changes in appearance was developed to monitor the duration in hour/ day of each phase from anthesis to flower fall or 
fruit initiation. The duration (in hours and/or days) of each floral phase was recorded for each flower from the period of pre-anthesis (bud) to flower or fruit shed or seed production. This scale was then used to study stigma receptivity in A. crassna.

\section{Stigma receptivity}

To study stigma receptivity, a modified procedure from Dafni \& Maués (1998) was used to identify esterase activity using a Peroxtesmo esterase indicator paper liquid (one paper $+1 \mathrm{ml}$ water). One indicator paper of PeroxtesmoKo- peroxidase $(15 \times 15 \mathrm{~mm})$ was soaked in $1 \mathrm{ml}$ of distilled water and a droplet of the solution was applied directly onto the stigma. From each species, 15 flowers at three different developmental stages (opening, fully open and closing/senescing flowers (Figure 1) were examined to determine receptivity (Heslop-Harrison \& Shivanna 1977). A dissecting microscope ( $\mathrm{x} 40$ ) was used to detect any reaction to the solution. The appearance of a blue colour indicates receptivity. Peroxidase activity was recorded as presence or absence of colouration (binary) on the stigmatic surface.

\section{Breeding system}

The breeding system of $A$. crassna was evaluated through a series of controlled hand pollinations as described by Bittencourt Jr \& Semir (2004) and Oliveira et al. (1992). Pollinations were made in two consecutive years (2014 \& 2015) in different trees each season. The trees used in the study were selected based on their availability of flowers in each season. Fourteen individuals were evaluated in 2014 and 20 individuals in 2015 . In the 2014 event, whole inflorescences were enclosed in bud stage using pollen proof bags
$(150 \times 200 \mathrm{~mm}, 12$ individuals) or fine mesh bags $(200 \times 250 \mathrm{~mm}, 2$ individuals). In 2015 only fine mesh bags were used to isolate the inflorescences and two techniques of hand pollination were tested in this year, hand-pollination in advanced bud stage (estimated to be within $24 \mathrm{hrs}$ of opening) and open flowers (enclosed at bud stage to prevent open pollination) (Figure 1). In both years flowers were emasculated prior to pollen shed, in 2014 they were emasculated as the flowers were opening, and in 2015 they were emasculated in both the advanced bud stage and during opening. The bags were secured to adjacent branches using flexible wire to limit their movement in the wind.

In both years, flowers were either hand pollinated using pollen from anthers of the same flower or another flower of the same tree (controlled self-pollination), or cross-pollinated with pollen from a distant tree of the same species (intraspecific cross-pollination). In 2015 controlled pollination of $A$. crassna with pollen from other two species, A. baillonii and $A$. subintegra, was also conducted. The interspecific crosses were in one direction, with $A$. crassna as the female parent as it was the most abundant species in the plantation. Interspecific crosses were performed to determine if crosses between species are possible under natural conditions as these three species are growing in close proximity.

Each tree, branch and inflorescence in both years was allocated a unique code according to its species and pollination treatment (open, spontaneous self- [bag control], controlled self-, intraspecific cross- and interspecific crosspollination). Hand pollination was carefully done covering the whole surface of the stigma with fresh pollen. Fruit set was recorded at fruit initiation stage in 2014. In 2015, seed production from the controlled pollination experiments

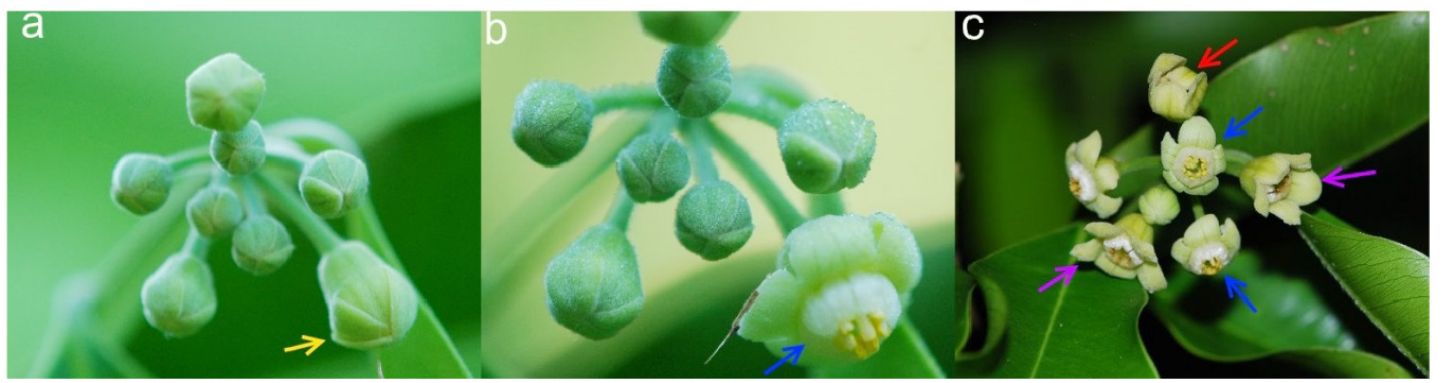

Figure 1 (a) Buds ready to open (opening stage), (b) anthesis (open stage), (c) floral developmental stages captured in a inflorescence of Aquilaria crassna [anthesis, closing stages, anthers wilted (orangebrownish), closed stage (tepals enclosing ovary), fruit initiation or flower fall] 
was recorded and seeds collected to check for embryo viability. For natural fruit set, flowers were tagged and monitored until fruit set and the presence or absence of fruit per inflorescence recorded.

\section{Data analysis}

Flower images were labelled and stacked using Image J and PaintNet. Four floral stages were defined by direct observation of flower morphology and assessment of images. The duration of the flowering stages was summarised using the time-labelled sequence of the images. The flower developmental stages were then used in the stigma receptivity analysis.

The differences in peroxidase activity across each flower developmental stages were analysed using a generalised linear model ( $\mathrm{glm}$ ) on binary outcome data with glm () function of the statistical package R (R Core Team 2015). Peroxidase activity was recorded as presence or absence of colouration on the stigmatic surface (response variable) at three stages of flower development (explanatory variable). Wald test was performed to account for the overall effect of flower developmental stages. A simple model was fitted (colouration $\sim$ flower stage). The overall fit of the model was conducted using likelihood ratio test. The $\mathrm{p}$-values of the tests were calculated using the $\mathrm{X}^{2}$ distribution.

Due to the nature of the results obtained in the breeding system observations (low success of fecudantion) it was not possible to analyse interactions between fruit production and pollination treatments [the data contained too many zeroes (failures) in the response variable] or year because different individuals were analysed each year (same trees did not flower two consecutive years). Therefore only percentage of success or failure in fruit production was presented.

\section{RESULTS}

\section{Reproductive phenology}

Flower changes during anthesis and fruit formation

Anthesis in A. crassna generally occurred between 5:00 pm and 7:00 am, although some flowers open during the daylight hours of the morning. The process of separation of the tepals until the flower is completely open may last up to one hour. Anthers change colour from yellow to orange-brownish after $23 \mathrm{~h}$ (range 11-48 h) of flower opening (Figure 2).

Four distinct stages of flower blooming

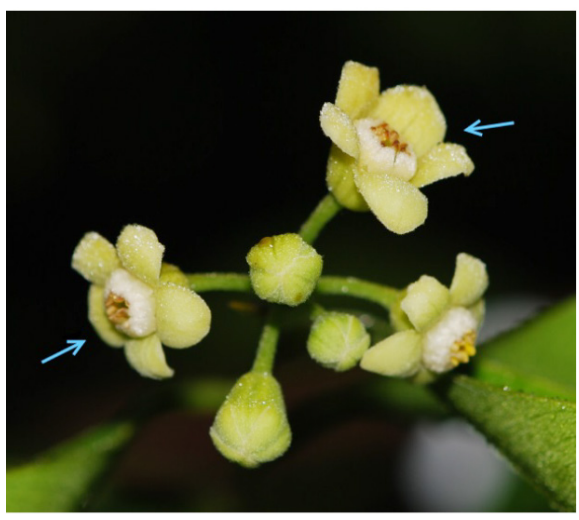

Figure 2 Anthers wilted (change in colour from yellowish to orange-brownish) after a range of 11 to $48 \mathrm{~h}$ after flower opening in Aquilaria crassna inflorescence

and flower senescent process were identified (opening, open, closing and closed) in $A$. crassna flowers (Figure 1). In the opening stage the tepals-buds were starting to open and are visibly loose. The process of separation of the tepals until flower is completely open may last up to one hour. In the opening stage the tepalsbuds were starting to open and seem loose. The process of separation of the tepals until flower is completely open may last up to one hour. In the open stage, tepals were unfolded and at $90^{\circ}$ angle to the flower axis. Flower remained open for an average of 2.13 days (range 1-3 days) in 2012 and 3.6 days (range 2-4 days) in 2015/2016. Anthers change colour from yellow to orangebrownish after $23 \mathrm{~h}$ (range 11-48 h) of flower anthesis. Flower remained open for an average of 2.13 days (range 1-3 days) in 2012 and 3.6 days (range 2-4 days) in 2015/2106. The open stage is concluded as the flower tepals begin to close (closing stage), and anthers begin to wilt, stigma turns orange leading to a closed stage of flower development. Flowers begin to close 1 to 4 days after anthesis. At the closed stage, tepals are folded but loose, non-fruiting flowers can persist in the inflorescence between 1 and 18 days until flower fall (Table 1). And flowers in which fruit initiation had occurred remained closed between 16 to 25 days (the tepals will remain attached to 


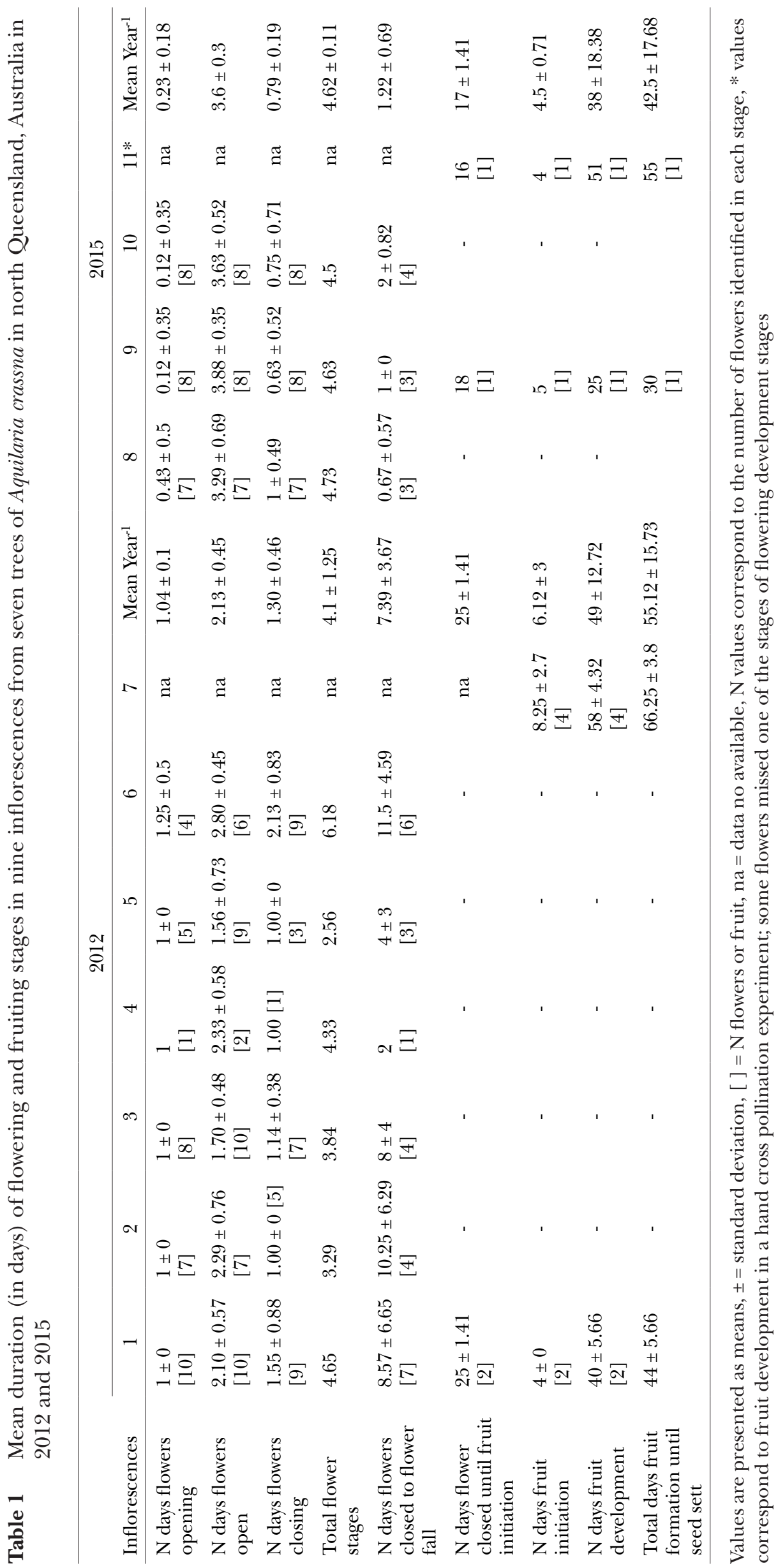


the developing fruit (Figure 3, Table 1). Flower fall occurred in average at day seven (range 1-20 days) after flower opening in 2012 and at day five (range 3-8 days) in 2015.

Two stages were identified in the fruit formation: fruit initiation and fruit maturity (until seed set) (Figure 3). Fruit initiation was recorded when there is evidence of size increment within the ovaries, stigma scar prominent; tepals expand to cover a quarter of the fruit. Fruit development can be recognised when fruits are rounded in the apex, with the tip extending beyond the level of the tepals; tepal colour changes slightly to brown. The duration from the beginning of fruit initiation until fruit opening ranged from 30 to 66 days (Table 1).

\section{Stigma receptivity}

The stigma was found to exhibit staining (indicating esterase activity) in 20, 100 and 27\% of flowers at opening, fully open and closing stages respectively (Table 2). At closing stage, the stigmatic surface normally turns orange so it was more difficult to distinguish the blue stain than in younger flowers with pale coloured stigmas. Four flowers $(27 \%)$ had evidence of blue stain indicating esterase activity. Flower developmental stages had a significant effect on the incidence of stigma staining with a significantly greater incidence recorded in flowers in the open stage compared with those in either opening or closing stages (Table 3).

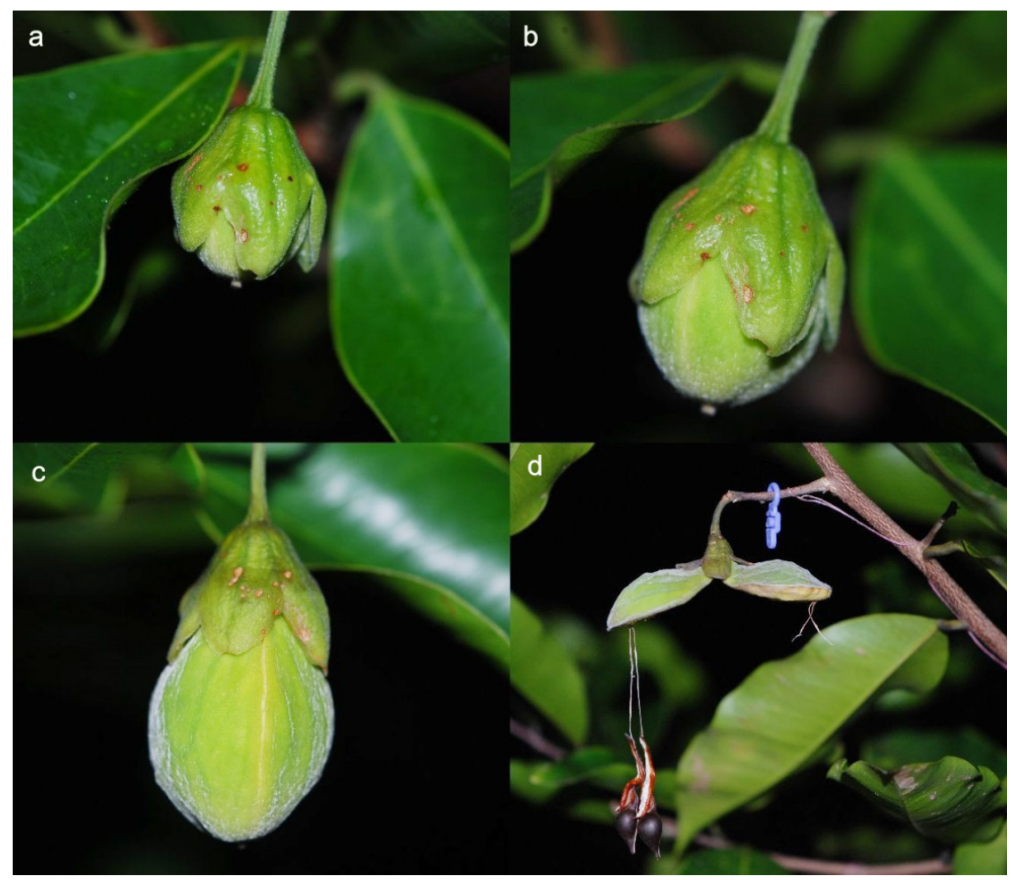

Figure 3 Fruit developmental stages identified in Aquilaria crassna (a) late stage of fruit initiation where the tip of the swollen ovaries almost reaches the level of the tepals, (b) early- to mid-fruit development stage where the ovaries have continued to expand beyond the level of the tepals (c) late fruit development and (d) fruit open with seed hanging from their arils by delicate threads (duration of hanging varies can last from several hours to days depending on prevailing wind conditions)

Table 2 Esterase activity recorded as a presence or absence of colouration in the stigma surface as indicative of receptivity in three stages of flowers development in cultivated Aquilaria crassna

\begin{tabular}{lcccccc}
\hline & \multicolumn{2}{c}{ Opening } & \multicolumn{2}{c}{ Open } & \multicolumn{2}{c}{ Closing } \\
\hline Species & Presence & Absence & Presence & Absence & Presence & Absence \\
Aquilaria crassna & $3(20 \%)$ & $12(80 \%)$ & $13(87 \%)$ & $2(13 \%)$ & $4(27 \%)$ & $11(73 \%)$ \\
\hline
\end{tabular}

$\mathrm{n}=15$ flowers per flower stage 
Table 3 Regression coefficients of a logistic regression model with generalised linear model (glm) () function testing for the effects of flower developmental stages on stigma receptivity of cultivated Aquilaria crassna

\begin{tabular}{lccccc}
\hline Coefficients & Estimate & SD & z value & $\operatorname{Pr}(>|\mathrm{z}|)$ & OR \\
\hline Intercept & -1.3863 & 0.6455 & -2.148 & $0.0317^{*}$ & 0.2500 \\
Open stage & 3.2581 & 0.9968 & 3.269 & $0.0011 * *$ & 26.000 \\
Closing stage & 0.3747 & 0.8704 & 0.430 & 0.6668 & 1.4545 \\
\hline
\end{tabular}

$\mathrm{OR}=$ odd ratios, null deviance $=61.827$ on 44 degrees of freedom, residual deviance $=44.190$ on 42 degrees of freedom, Akaike information criterion $(\mathrm{AIC})=50.19$, number of Fisher Scoring iterations $=4$

The model testing for the effects of flower developmental stages on stigma receptivity is $\mathrm{X}^{2}=17.63678$ with $\mathrm{p}<0.001$. In the case of having a flower in open stage $\mathrm{v}$ opening stage, the odds ratio of a receptive stigma increase by a factor of 26 .

\section{Breeding system}

Percentage fruit set recorded in this study was greater in open-pollinated flowers than hand cross-pollinated flowers across both years (Table 4, Figure 4). Natural fruit set exceeded that of hand cross-pollinated flowers almost by a factor of three in 2014 and by a factor of five in 2015 . None $(0 \%)$ of flowers set fruit when A. crassna was tested for spontaneous self-pollination (bagged but not pollinated) and hand self-pollination in 2014. In 2015, $1.4 \%$ of fruit production was recorded in selfpollination experiments and $2.2 \%$ for hand self-pollination performed in open flowers (Table 4). Fruit set in intraspecific crosses was $6 \%$ and $2.1 \%$ in 2014 and 2015, respectively. Interspecific crosses between $A$. crassna and A. baillonii reached $4.7 \%$ fruit set, whereas interspecific crosses between $A$. crassna and $A$. subintegra did not produce any fruit. Values for fruit set by pollination technique (at bud stage or open flower), were similar for intraspecific and interspecific crosses, however in the case of controlled self-pollination only for open flower pollination technique fruit production $(2.2 \%)$ was recorded (Table 4$)$. Flowers dried out and fell off after a few days following hand self-pollination or bagging. Germination rate for open pollination experiment was $88 \%$ and for the controlled crosses all seeds sown germinated.

\section{DISCUSSION}

\section{Reproductive phenology}

The A. crassna trees in north Queensland flower between early-October to mid-November (midto late-dry season). Flowering in the dry season has been recorded for other Aquilaria spp. growing in natural and cultivated environment in Indonesia (Soehartono \& Newton 2001). In this study, fruit development took place during November-December.

The inflorescence of $A$. crassna can have up to seven flowers that open gradually and sometimes synchronised (two flowers open at one time) and differently orientated (Figure 1). Gradual and sometimes synchronised availability of two flowers in an inflorescence, differently orientated, combined with longevity (capacity to stay open for 2-4 days) may help in the attraction of and facilitate access for pollinators and might also reduce the potential of geitonogamy (Johnston 1991, Roccotiello et al. 2009).

The duration of flowering and fruiting documented for A. crassna in this study were similar to other species of the genus Aquilaria growing in plantations. For example, A. crassna flowering stage in the study lasted 2 to 4 more days, respectively, than the reproductive stages reported for A. crassna and A. filaria growing in Indonesia (Soehartono \& Newton 2001). Similar patterns in duration (number of days) of flowering were observed in A. hirta, A. malaccensis and $A$. microcarpa. Fruit development in the study ranged from 30 to 66 days, similar to what has been reported by Soehartono \& Newton (2001) for A. crassna, A. filaria, A. microcarpa, A. beccariana, A. hirta, and A. malaccensis. 
Table 4 Number of fruit set and seed produced by cultivated Aquilaria crassna in north Queensland, Australia

\begin{tabular}{|c|c|c|c|c|c|c|c|c|c|c|}
\hline \multirow[b]{2}{*}{ Experiment } & \multicolumn{5}{|c|}{2014} & \multicolumn{5}{|c|}{2015} \\
\hline & $\begin{array}{l}\mathrm{N} \\
\text { trees }\end{array}$ & $\begin{array}{c}\mathrm{N} \\
\text { flowers }\end{array}$ & $\begin{array}{l}\mathrm{N} \\
\text { fruits }\end{array}$ & $\begin{array}{c}\mathrm{N} \\
\text { seeds }\end{array}$ & $\begin{array}{c}\% \\
\text { success }\end{array}$ & $\begin{array}{l}\mathrm{N} \\
\text { trees }\end{array}$ & $\begin{array}{c}\mathrm{N} \\
\text { flowers }\end{array}$ & $\begin{array}{l}\mathrm{N} \\
\text { fruits }\end{array}$ & $\begin{array}{c}\mathrm{N} \\
\text { seeds }\end{array}$ & $\begin{array}{c}\% \\
\text { success }\end{array}$ \\
\hline $\begin{array}{l}\text { Spontaneous self-pollination } \\
\text { (bag control) }\end{array}$ & 3 & 143 & 0 & na & $0 \%$ & 4 & 211 & 3 & 2 & $1.4 \%$ \\
\hline $\begin{array}{l}\text { Controlled self-pollination } \\
\text { (bud pollination) }\end{array}$ & 4 & 47 & 0 & na & $0 \%$ & 4 & 105 & 0 & 0 & $0 \%$ \\
\hline $\begin{array}{l}\text { Hand self-pollination } \\
\text { (flower pollination) }\end{array}$ & na & na & na & na & na & 2 & 45 & 1 & $*$ & $2.2 \%$ \\
\hline $\begin{array}{l}\text { Intraspecific cross pollination } \\
\text { (bud pollination) }\end{array}$ & 4 & 50 & 3 & na & $6 \%$ & 6 & 193 & 5 & 5 & $2.6 \%$ \\
\hline $\begin{array}{l}\text { Intraspecific cross pollination } \\
\text { (flower pollination) }\end{array}$ & na & na & na & na & na & 3 & 48 & 1 & 2 & $2.1 \%$ \\
\hline $\begin{array}{l}\text { Interspecific cross pollination } \\
\text { (bud pollination } \mathrm{Ac} \times \mathrm{Ab} \text { ) }\end{array}$ & na & na & na & na & na & 4 & 85 & 4 & 5 & $4.7 \%$ \\
\hline $\begin{array}{l}\text { Interspecific cross pollination } \\
\text { (bud pollination Ac } \mathrm{x} \text { As) }\end{array}$ & na & na & na & na & na & 4 & 123 & 0 & 0 & $0 \%$ \\
\hline $\begin{array}{l}\text { Interspecific cross pollination } \\
\text { (flower pollination } \mathrm{Ac} \times \mathrm{Ab} \text { ) }\end{array}$ & na & na & na & na & na & 2 & 38 & 2 & 0 & $5.2 \%$ \\
\hline $\begin{array}{l}\text { Interspecific cross pollination } \\
\text { (flower pollination Ac x As) }\end{array}$ & na & na & na & na & na & 3 & 21 & 0 & 0 & $0 \%$ \\
\hline Open pollination & 3 & 331 & 48 & na & $14.5 \%$ & 18 & 956 & 446 & 576 & $46.7 \%$ \\
\hline
\end{tabular}

$\mathrm{Na}=$ no data available, $*$ seed missing at the time of counting, $\mathrm{Ac}=$ Aquilaria crassna, $\mathrm{Ab}=$ A. baillonii, $\mathrm{As}=$ A. subintegra

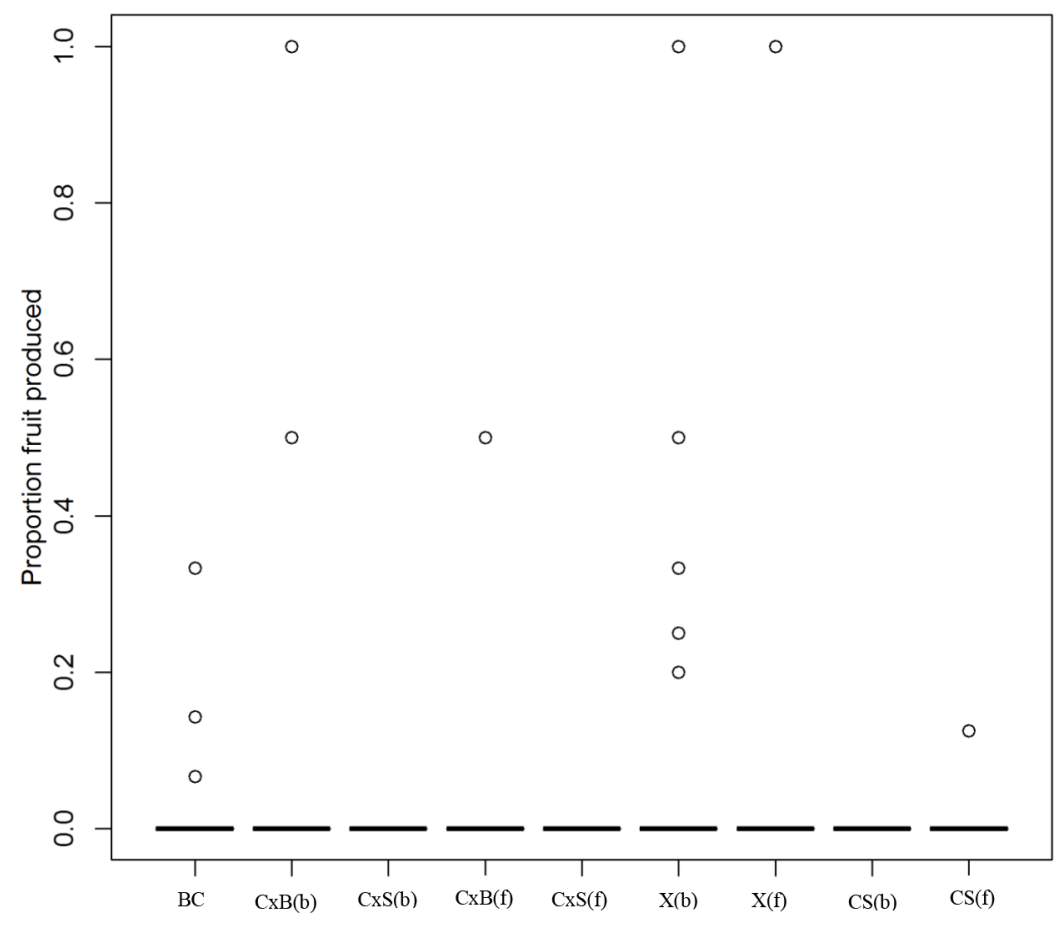

Figure 4 Proportion of fruit produced by experiment in both years of data collection, $\mathrm{BC}=\mathrm{bag} \mathrm{control} /$ spontaneous self-pollination, $\mathrm{C}$ x $\mathrm{B}=$ inter-crosses $A$. crassna x A. baillonii, $\mathrm{C} \times \mathrm{S}=$ inter-crosses $A$. crassna $\mathrm{x}$ A. subintegra, $\mathrm{X}=$ intra crosses, $\mathrm{CS}=$ control self-pollination; letters in parentheses denote the flower stage at time of controlled pollination $(\mathrm{b})=$ buds and $(\mathrm{f})=$ flowers 


\section{Flower changes during anthesis and stigma receptivity}

Anthesis in A. crassna generally occured in the evening and early morning; the stigma was receptive during the open stage of the flower development and pollen shed was largely completed on average within $23 \mathrm{~h}$ after anthesis (Table 2). In other members of the Thymelaeaceae family (e.g. Diplomorpha spp) it has been reported that anthesis occurs at dusk; the stigma is receptive during the open stage of the flower scale and pollen shed is largely completed on average within $23 \mathrm{~h}$ after anthesis. In this research a higher level of insect flower visitors was observed at night compared with the day. This trend has been observed by other researchers when studying visitors of Aquilaria spp. flowers (Soehartono \& Newton 2001, Tasen et al. 2009). More research is required to quantify foraging activity of flowers' visitors in A. crassna growing in Queensland.

\section{Breeding systems}

\section{Open pollination}

In this study open pollinated $A$. crassna flowers had high fecundity in both years, however fruit production in $2015(46.7 \%)$ was greater than $2014(14.5 \%)$. The difference may be influenced by the different genotypes used, agronomical practices (insect pest control that could also affect pollinator populations), resource availability and/or seasonal effects. Further research is required to determine the relative influence of these factors on percentage fruit set. The percentage of open-pollinated flowers in A. crassna in this study (14.5 to $46.7 \%$ ) was greater than the reported by Tasen et al. (2009) for A. crassna growing in plantation (3\% fruit set) and natural stands (2\% fruit set).

\section{Controlled pollination experiments (self-pollination and intra-inter crosses)}

A high rate of failure in hand-pollinated flowers of $A$. crassna was recorded in both years, where more than $90 \%$ of the flowers were shed after pollination. This high rate was consistent between the two methods where hand-pollination was carried out in buds (closed but about to open) or recently open flowers (2015 data). One possible explanation for the low rates of fruit set in controlled-pollination treatments is the flower sensitivity to handling and bagging; the flowers suffered desiccation after pollination, suggesting that further refinement of controlled pollination techniques would be required before it could be used routinely in plant breeding. Young \& Young (1992) suggested possible reasons of low reproductive success in controlled pollination experiments in comparison with natural pollination, for instance, emasculation and pollen application to the stigma can cause mechanical damage resulting in flower abortion. Mechanical damage can also be sustained during installation and removal of isolation bags, and through the effects of wind. The bags can potentially increase the temperature and humidity within, particularly for the more impervious woven bags. Controlled pollination of A. crassna was found to be challenging with a high level of flower abortion, possibly due to their sensitivity to the handling (emasculation \& pollination) and isolation (bagging) procedures. Results may be considered to be indicative of the breeding system in $A$. crassna due to the low reproductive success.

The index of self-incompatibility developed by (Ruiz \& Arroyo 1978) is calculated by the mean number of fruits per pollinated flower in selfexperiments divided by intra-cross experiments. Species may be defined as (a) self-compatible (score $=1)$, (b) incompletely compatible (score between 1 and 0 ) or (c) self-incompatible (score $=0)$. A. crassna may be considered to be partially self-compatible $($ score $=0.33)$. Over the two seasons evaluated in this study, the proportion of individuals producing fruits following intraspecific cross-pollination $(43 \%)$ was greater than the number of trees that produced fruits after self-pollination (24\%). Variation in the level of apparent self-incompatibility between individuals has also been demonstrated for two species of Santalum, i.e. S. lanceolatum where only $20 \%$ of genotypes had a capacity for producing self-seed and S. spicatum with a high level of inbreeding in one half-sib family, but a high mean outcrossing rate $(95.2 \%)$ in all remaining families (Muir et al. 2007, Tamla et al. 2011). Ceiba pentandra populations occurring in a tropical forest fragment had a mixed-mating system, with trees being partially self-compatible and with values for outcrossing of 40\% (Quesada et al. 2004). 
The results of the controlled cross-pollination observations in this study were consistent with other studies of $A$. crassna breeding system. Tasen et al. (2009) showed that the maximum of fruit production attained in controlled-cross pollination experiment was $3 \%$ to $4 \%$. In this study the ranges of fruit success for intra-crosses [6\% in 2014 and 2.1 (flower pollination) to $2.6 \%$ (bud pollination) in 2015] are similar to those reported by Tasen. The level of fruit set in controlled cross-pollination in our experiment was significantly lower than for open pollination, but such a difference was not recorded by Tasen et al. (2009). In the present experiment the level of open pollinated fruit set in 2015 was greater than 2014, but the opposite was found in cross pollination $(2014<2015)$. Preferential maternal resource allocation to open pollinated flowers without mechanical damage may be operating in this species.

Hybridisation between A. crassna and A. baillonii was achieved in the controlled pollination experiments, indicating a possible lack of or incomplete reproductive barrier between them. This is an important consideration for the development of agarwood as a forestry crop, particularly when multi-species plantations are being used as seed sources to establish new plantings. There is need for further research on the impact of hybrids on traits that are important to silvicultural management and resin qualities. López-Sampson \& Page (2018) detailed the differences in the properties of fragrant resin between species as well as historical and regional market preferences for particular species. Properties of and market acceptance of resins produced by hybrids will need to be further evaluated to determine their utility in the domestication of agarwood. While no successful hybrids were produced between $A$. crassna and A. subintegra, further refinement of pollination techniques is required to more thoroughly evaluate any potential barriers between these species.

In this research, seeds collected from the controlled pollination experiments were germinated and no differences in seedling vigour were recorded between pollination treatments over the first twelve months. However, seedlings from these experiments need to be grown and evaluated until the next generation to determine sexual function of their flowers and viability of resulting seed. Further research is required to evaluate the vigour of seedlings produced by inter crosses, as in this research it was not possible to evaluate seedling growth of controlled pollination observations.

\section{CONGLUSIONS}

Flowering and fruiting patterns of A. crassna can be described using simple development scale based on visible changes experimented by the reproductive structure. The annual flowering period was concentrated in the dry season and fruiting period in the wet season. The duration of flowering and fruiting stages of A. crassna lasted up to 9 weeks and were in similar ranges to that reported in other studies of its conspecific. Flowers of $A$. crassna remained open $>3$ days and anthesis generally started between $6: 00 \mathrm{pm}$ and 7:00 am with some flower opening during the daylight in the morning. Four anthesis stages were clearly identified: opening ( 0.2 to 1 day), open (2.3 to 3.6 days), closing (0.8 to 1.3 days) and closed-flower fall (1.4 to 7.4 days) or closed-fruit development (17 to 25 days). Percentage fruit set in controlled pollinated flowers was generally lower (0 to $6 \%$ ) than for open pollinated flowers (14.5 to $46.7 \%$ ). Hybridisation between A. crassna and $A$. baillonii was observed in this study but not between $A$. crassna and A. subintegra.

\section{ACKNOWLEDGMENTS}

This research was conducted in Wescorp Agarwood research plantation. López-Sampson A received an Australia Award Postgraduate Scholarship (AusAID). Sosnin A recorded images of inflorescence development in 2012.

\section{REFERENCES}

Azren PD, Lee SY, Emang D \& Mohamed R. 2018. History and perspectives of induction technology for agarwood production from cultivated Aquilaria in Asia: a review. Journal of Forestry Research 30: 1-11.

Akter S, Islam MT, Zulkefeli M \& Khan SI. 2013. Agarwood production-A multidisciplinary field to be explored in Bangladesh. International Journal of Pharmaceutical and Life Sciences 2: 22-32.

Barden A, Anak NA, Mulliken T \& Song M. 2000. Heart of the Matter: Agarwood Use and Trade and CITES Implementation for Aquilaria malaccensis. Traffic-Cites, Traffic International, Cambridge.

Bittencourt Jr NS \& Semir J. 2004. Pollination biology and breeding system of Zeyheria montana (Bignoniaceae). Plant Systematics and Evolution 247: 241-254. 
DAFNI A \& MAUÉs MM. 1998. A rapid and simple procedure to determine stigma receptivity. Sexual Plant Reproduction 11: $177-180$

Donovan DG \& PURI RK. 2004. Learning from traditional knowledge of non-timber forest products: Penan Benalui and the autecology of Aquilaria in Indonesian Borneo. Ecology and Society 9: 3.

Heslop-Harrison Y \& Shivanna KR. 1977. The receptive surface of the angiosperm stigma. Annals of Botany 41: $1233-1258$.

JoHnSTON MO. 1991. Natural selection on floral traits in two species of Lobelia with different pollinators. Evolution 45: 1468.

LiU Y, Chen H, Yang Y et AL. 2013. Whole-tree agarwoodinducing technique: An efficient novel technique for producing high-quality agarwood in cultivated Aquilaria sinensis trees. Molecules 18: 3086-3106.

López-Sampson A \& Page T. 2018. History of Use and Trade of Agarwood. Economic Botany 72: 107-129.

MoHAmed R, Jong PL \& KamZiah AK. 2014. Fungal inoculation induces agarwood in young Aquilaria malaccensis trees in the nursery. Journal of Forestry Research 25: 201-204.

Muir K, Byrne M, Barbour EL, Cox MC. \& Fox JED. 2007. High levels of out-crossing in a family trial in Western Australia sandalwood (Santalum spicatum). Silvae Genetica 56: 222-230.

Nakashima EMN, Nguyen MTT, Tran QL \& Kadota S. 2005. Field survey of agarwood cultivation at Phu Quoc Island in Vietnam. Journal of Traditional Medicines 22: 296-300.

Ng LT, Chang YS \& Kadir AA. 1997. A review on agar (gaharu) producing Aquilaria species. Journal of Tropical Forest Products 2: 272-285.

Oliveira PE, Gibbs PE, Barbosa AA \& Talavera S. 1992. Contrasting breeding systems in two Eriotheca (Bombacaceae) species of the Brazilian cerrados. Plant Systematics and Evolution 179: 207-219.

Page T \& Awarau W. 2012. Performance of agarwood (Aquilaria crassna) seedling transplants improved by shade and fertiliser. Forest Ecology and Management 265: 258-269.

Persoon GA. 2008. Growing 'the wood of the gods': agarwood production in Southeast Asia. Pp 245-262 in Snelder DJ \& Lasco RD (eds) Smallholder Tree Growing for Rural Development and Environmental Services: Lessons from Asia. Springer, Dordrecht.

Parr A \& Cameron AD. 2004. Effects of tree selection on strength properties and distribution of structural roots of clonal Sitka spruce. Forest Ecology and Management 195(1-2), 97-106. doi: http://dx.doi. org/10.1016/j.foreco.2004.02.033

Quesada M, Stoner KE, Lobo JA et al. 2004. Effects of forest fragmentations on pollinator activity and consequences for plant reproductive success and mating patterns in bat-pollinated Bombacaceous trees. Biotropica 36: 131-138.

R Core Team. 2015. R: A Language and Environment for Statistical Computing. R Foundation for Statistical Computing,Vienna.

Rahman M \& Khisa S. 1984. Agar production in agar tree by artificial inoculation and wounding. II. Further evidences in favour of agar formation. Bano Biggyan Patrika 13: 57-63.

Rasool S \& MoHamed R. 2016. Understanding agarwood formation and its challenge. Pp 39-56 in Mohamed $\mathrm{R}$ (ed) Agarwood: Science Behind the Fragrance. Springer, Singapore.

Roccotiello E, Casazza G, Galli L, Cornara L, Moncalvo A \& Minuto L. 2009. The flower biology of Daphne gnidium L. (Thymelaeaceae). Plant Systematics and Evolution 279: 41-49.

Ruiz ZT \& ARroyo KMT. 1978. Plant reproductive ecology of a secondary decidous tropical forest in Venezuela. Biotropica 10: 221-230.

Soemartono T \& Newton AC. 2000. Conservation and sustainable use of tropical trees in the genus Aquilaria I. Status and distribution in Indonesia. Biological Conservation 96: 83-94.

Soehartono T \& Newton AC. 2001. Reproductive ecology of Aquilaria spp. in Indonesia. Forest Ecology and Management 152: 59-71.

Tamla HT, Cornelius JP \& Page T. 2011. Reproductive biology of three commercially valuable Santalum species: development of flowers and inflorescences, breeding systems, and interspecific crossability. Euphytica 184: 323-333.

Tasen W, Tangmitcharoen S, Thakeaw M \& Ogata K. 2009. Insect pollination of Aquilaria crassna (Thymelaeaceae): Effect of moths for the fruit setting in Thailand. Journal of the Faculty of Agriculture, Kyushu University 54: 321-328.

Young HJ \& Young TP. 1992. Alternative outcomes of natural and experimentall high pollen loads. Ecology 73: 639-647. 